\title{
HISTÓRIA \\ LAÇOS INCERTOS NAS RELAÇÕES POLÍTICAS ENTRE BRASIL E PORTUGAL NA DÉCADA DE 1960 Cristina luskow \\ LAÇOS INCERTOS NAS RELAÇÕES POLÍTICAS ENTRE BRASIL E PORTUGAL NA DÉCADA DE $1960^{1}$
}

\section{UNCERTAIN TIES IN POLITICAL RELATIONS BETWEEN BRAZIL AND PORTUGALIN THE 1960S}

Cristina luskow ${ }^{2}$

\begin{abstract}
Resumo: Este artigo tem como objetivo tratar da inserção da Revista Luso Brasileira na cidade de Florianópolis nas décadas de 1960 e 1970, publicação catarinense, que circulou entre 1961 e 1979, fundada pelo português Mario Fernandes Dias, emigrado de Portugal para Florianópolis em 1958. Contemplava diversos assuntos desde culinária à vida política de Portugal e do Brasil, entremeados por anúncios de comércio local. Seus mil exemplares eram enviados ainda para Portugal, Angola, Cabo Verde e outras cidades do Brasil. Buscarei aqui compreender as temáticas tratadas pela revista e as relações estabelecidas com os regimes de Portugal e Brasil, nas suas variações políticas, e, além disso, perceber como a publicação se relacionava com a política e comunidade local, por meio do tratamento dos periódicos, percebidos aqui como fonte essencial no estudo da história do tempo presente.
\end{abstract}

Palavras-chave: História do Tempo Presente; Relações Brasil-Portugal; Imprensa.

Abstract: This article aims to address the insertion of the Revista Luso Brasileira in the city of Florianópolis in the 1960s and 1970s, a publication in Santa Catarina, circulated between 1961 and 1979, founded by the Portuguese Mario Fernandes Dias, emigrated from Portugal to Florianópolis in 1958. subjects ranging from culinary to political life in Portugal and Brazil, interspersed with local commercial announcements. Its thousand copies were still sent to Portugal, Angola, Cape Verde and other cities of Brazil. I shall endeavor here to understand the themes dealt with by the journal and the relations established with the regimes of Portugal and Brazil in their political variations, and also to understand how the publication related to the local politics and community through the treatment of newspapers, perceived here as an essential source in the study of the history of the present time.

Keywords: History of Present Time; Brazil-Portugal relations; Press.

A partir da publicação da Revista Luso-Brasileira surgida em Florianópolis nos anos de 1960, a capital de Santa Catarina passou a agrupar uma comunidade de portugueses que extrapolava suas limitadas dimensões e a situar-se entre aquelas que terão certa relevância para o conjunto de cidades no mundo lusófono, por então

\footnotetext{
${ }^{1}$ Este artigo é fruto de pesquisa de doutorado com financiamento da CAPES.

2 Doutoranda em História pela Universidade do Estado de Santa Catarina na linha de pesquisa Culturas Políticas e Sociabilidades.
} 
LAÇOS INCERTOS NAS RELAÇÕES POLÍTICAS ENTRE BRASIL E PORTUGAL NA DÉCADA DE 1960 Cristina luskow

abrigarem um grupo de portugueses e um periódico luso-brasileiro que terá alguma expressão na política portuguesa de então. Durante 18 anos a revista atuou e serviria de referência para os que se diziam parte da pátria portuguesa espalhada pelo mundo. Ao se conhecer mais de perto a publicação, passam a ser conhecidos nomes, eventos, datas e lugares que demonstram haver um interesse em reunir e fortalecer uma comunidade denominada luso-brasileira, caracterizada como um grupo de pessoas com uma mesma língua, um passado em comum e que pudessem também ter interesses em comum no que diz respeito aos países que reuniam povos de língua portuguesa.

A parte lusa da comunidade luso-brasileira em Florianópolis e também no restante do país tem uma trajetória com peculiaridades, em que se poderia afirmar que são imigrantes que carregam uma carga política e ideológica consigo. Sair de Portugal em meio a um regime ditatorial que ansiava por manter o sentimento de "portugalidade"3 na abrangência do seu "império colonial" era tarefa por vezes carregada de um compromisso com o regime salazarista. O Estado Novo, regime autoritário imposto ao país europeu a partir de desdobramentos de um golpe de Estado em 1926, enfrentou uma imprevista emigração maciça como afirma Weslei Rodrigues $(2013,52)$. Ao mesmo tempo que o regime procurava criar a imagem do português ideal como camponês, voltado ao mundo rural, enfrentava também a emigração em grande escala. Diante desse quadro, concentrou-se em enfrentar a emigração buscando incorporá-la em um modelo de nação imaginada, conclui Rodrigues $(2013,52)$. Esse modelo passava pela representação e o apoio ao regime fora de Portugal, pela união das colônias portuguesas para manter as tradições, a manutenção do sentimento de pertencimento lusitano e a defesa dos ideais do Estado Novo português. Os emigrantes portugueses no Brasil, que partiram com a aprovação do regime, aqui viviam como se estivessem em uma extensão do Estado Novo no além-mar. Não era esperado que "dessem as costas" a Portugal, mas pelo

\footnotetext{
3 “O conceito perseguia a ideia de que as ex-colónias fossem vistas pela ONU não como territórios autónomos, mas como parte integrante de Portugal. Tratou-se de um processo que avançou de forma acentuada após a revogação, em 1951, do Ato Colonial de 1930, em que as colónias passaram a denominar-se províncias ultramarinas. [...] a partir dessa altura, mais exatamente desde 27 de abril de 1951, [os deputados na Assembleia Nacional] utilizam pela primeira vez a palavra 'portugalidade' nas intervenções parlamentares sublinhando, assim, no discurso político, a 'portugalidade' como sinónimo de Portugal e as suas colónias como um todo uno e indivisível, traduzido pela frase "Portugal do Minho a Timor" (SOUSA, 2017, 2).
} 


\section{HISTÓRIA}

LAÇOS INCERTOS NAS RELAÇÕES POLÍTICAS ENTRE BRASIL E PORTUGAL NA DÉCADA DE 1960 Cristina luskow

contrário, que apoiassem as suas políticas no Brasil por meio das associações, reuniões e da imprensa, e de campanhas feitas em nome dos interesses portugueses.

A Revista Luso-Brasileira circulou entre 1961 e 1979, era publicada em Florianópolis, mas distribuída entre cidades no Brasil, Portugal e cidades africanas em colônias portuguesas (assim nominadas até 1975 quando começam a ocorrer as independências). Havia correspondentes da revista espalhados em Angola, Cabo Verde, Portugal, Ilha da Madeira e no Paraná, informação esta que consta do cabeçalho dos números do periódico. Por seu formato, capa e conteúdo, o periódico apresentava-se como de entretenimento, mas também como informativo e noticioso, com 20 páginas impressas, ilustrações feitas em quatro cores primárias, folhas de $31 \mathrm{~cm} \times 24 \mathrm{~cm}$ e notícias e imagens variadas que ilustram muitos de seus espaços. Os textos da revista versavam sobre temas variados, dentre os quais, moda feminina, lidas domésticas, conteúdo sobre pais e filhos, contos, poesias, piadas, receitas culinárias, eventos sociais e colunas sociais. Mas, havia também notícias densas sobre a política portuguesa e brasileira. Portanto, para isso, os editores através dos correspondentes traziam notícias sempre atualizadas de Portugal, fossem estas econômicas, políticas ou artístico-culturais. Por meio dessas notícias, informações e crônicas que permeavam o periódico, difundiu-se ao longo dos dezoito anos da publicação a "cultura portuguesa", ou uma cultura política de Portugal que chegava aos emigrados portugueses em Florianópolis e nas cidades em que houvesse portugueses emigrados alcançados pela revista. Além desses era importante também que brasileiros se identificassem com as histórias de Portugal e com as notícias que chegavam de lá, que pudessem se familiarizar com elas a ponto de querer apoiar seus propósitos no contexto da manutenção do seu império ultramarino.

A divulgação da revista se fazia necessária dentro da lógica de difusão de uma cultura portuguesa, ligada ao desejo do Estado Novo em fortalecer a comunidade luso-brasileira no Brasil por meio de periódicos e que esta cultivasse vínculos com seu país de origem e com a comunidade portuguesa pelo mundo. Procurava-se unir, pelo sentimento de brasilidade e portugalidade, povos que se diziam "irmãos", e apelar para estes sentimentos com o intuito de resolver as dificuldades de Portugal em relação à sua política colonialista. 
LAÇOS INCERTOS NAS RELAÇÕES POLÍTICAS ENTRE BRASIL E PORTUGAL NA DÉCADA DE 1960 Cristina luskow

Cabe aqui uma pequena reflexão sobre periódicos, e remeto ao que afirma Tania Regina de Luca, quando aponta que estes são polos em que se reúnem forças de combate e intervenção no espaço público. E ainda oferecem oportunidades para dotar de conteúdo os embates em torno de interesses políticos e artístico-literários, ao mesmo tempo em que dialogam com os dilemas do tempo (DE LUCA, 2011, 2). Diante dessa observação e analisando o teor da revista e o meio em que circula, posso afirmar que a sua proposta seria a de realizar intervenções no espaço público de Florianópolis, das outras cidades do Brasil e do mundo de língua portuguesa em que circulava, trazendo para a discussão conteúdos ligados à questão política de Portugal. Ao longo do tempo, tornaram-se mais nítidos na narrativa da revista os projetos políticos que procuravam delinear, e de que forma os grupos que protagonizavam sua proposta se colocavam no espaço público e nos embates que aí se davam.

Este artigo procura destacar a construção da representação das ideias políticas que se constroem na Revista Luso-Brasileira em matérias pontuais apresentadas pelo periódico. Há o intuito aqui de procurar compreender como se dá o imbricamento entre uma história do Estado Novo português e a história da revista Luso-Brasileira, no contexto político-cultural brasileiro. No interior de um regime que tinha como uma de suas prioridades manter os laços entre os portugueses que deixaram o país, a atenção que se dá aos jornais e revistas luso-brasileiros que circulam pelo Brasil a partir da década de 1960 será fundamental para manter um ligame com os emigrados e também criar uma rede de comunicação entre Portugal e seus cidadãos fora do país. Tornava-se vital para o Estado Novo no início da década de 1960 o fortalecimento desta rede, pois a partir de 1961 se iniciam em Angola as guerras pela independência. Ora, a sobrevivência do Estado Novo português passava pela manutenção do colonialismo. Portanto, manter uma rede de influência em um país como o Brasil, que possui uma significativa colônia portuguesa ${ }^{4}$, será fulcral para que Portugal se mantenha impávido neste cenário, diante de grande pressão internacional a favor da autodeterminação dos povos. É importante salientar que essa rede não será formada somente entre os emigrados

\footnotetext{
${ }^{4}$ Entre 1950-1959 entraram no Brasil 237.327 portugueses e entre 1960-1969 serão 73.267 portugueses a entrar no país, houve uma queda, porém com um contingente ainda bastante significativo (PORTUGAL, RELATÓRIO DA EMIGRAÇÃO, 2013,19).
} 


\section{HISTÓRIA}

LAÇOS INCERTOS NAS RELAÇõES POLÍTICAS ENTRE BRASIL E PORTUGAL NA DÉCADA DE 1960 Cristina luskow

portugueses, mas muito solicitado também o apoio de brasileiros simpatizantes de Portugal e do ditador Salazar.

O Brasil, pelo fato de possuir a maior colônia de portugueses emigrados receberá uma maior atenção do Estado Novo direcionada ao cidadão que emigra. Florianópolis não possuía uma grande comunidade lusa, mas havia um pequeno grupo que vivia na cidade desde finais da década de 1950, pessoas que vieram sozinhas, encontraram conterrâneos, formaram famílias, estabeleceram negócios. Era para esse grupo de pessoas em Florianópolis, além dos brasileiros, que a Revista Luso-Brasileira estava direcionada. Na intenção de reunir esse grupo e fortalecer os "laços de amizade", o periódico veiculava suas histórias e trazia notícias de Portugal, relembrando para estes portugueses a sua origem, seu passado, suas tradições, seus símbolos. Mas não somente para o passado, chamava atenção também para o presente sobre o qual pulsavam os problemas de Portugal, as guerras anticolonialistas na África, seus embates na ONU, enfim para questões nas quais a manutenção da nação portuguesa, acreditava-se, poderia estar em risco.

Em meio a este contexto político, a chegada de Mario Fernandes Dias em Florianópolis, o imigrante português fundador da revista, se fará imbuída de um compromisso como "cidadão" português que longe do seu país trabalha com sentimento de engajamento na política do regime. Mario Dias ao deixar Portugal se categoriza como "cidadão" português, no sentido de que aceita as prerrogativas do Estado Novo e apoia tal política. Chegando ao Brasil esse posicionamento será mantido, e a análise da revista confirma seu comprometimento com as políticas portuguesas, internas ou externas.

Na edição de dezembro de 1968, a Revista Luso-Brasileira, apresenta na capa uma imagem emblemática: a figura católica de Maria segurando o filho Jesus (Figura 1). A figura de Maria está envolvida num manto que estampa a bandeira de Portugal e o menino envolto em outro manto com a estampa da bandeira do Brasil, evidenciando em primeiro plano as palavras Ordem e Progresso. Portugal simbolizando a mãe que por sua vez deu a vida ao filho chamado Brasil, representado aqui por um bebê. Nenhuma mensagem específica natalina, mas acima da imagem a frase que acompanha a revista: Um laço de Amizade entre Brasil e Portugal. As pequenas mãos do menino no rosto da mãe demonstram o carinho e a amizade. No 
entanto, as relações entre Brasil e Portugal nesse momento não eram as mais promissoras.

Figura 1 - Natal de 1968

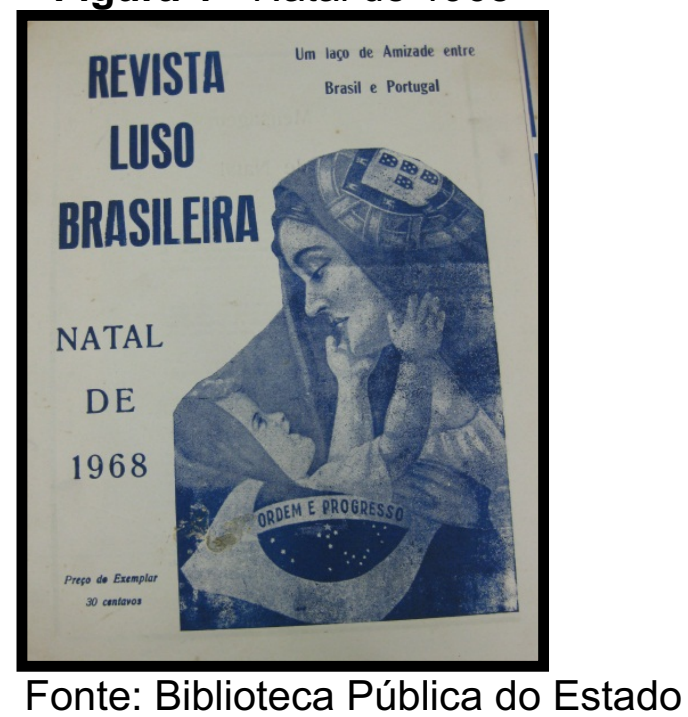

De Santa Catarina.

Ao longo das décadas de 1960 e 1970 ocorreram alterações no teor das relações entre Brasil e Portugal, criaram-se laços que foram se estreitando e laços que se desfizeram. Desde 1933 Portugal vivia sob o Estado Novo, implantado por António de Oliveira Salazar, que permaneceu vigente por 41 anos. Antes de se instaurar o Estado Novo, o país foi alvo, em 1926, de um golpe militar que derrubou a Primeira República no país. O Estado Novo, que teve à frente a figura de Salazar até 1969, sucedido por Marcello Caetano até seu final em 1974, será o período histórico aqui investigado, com foco específico nas décadas de 1960 e 1970. De 1933 a 1974 as transformações no direcionamento da política portuguesa em relação ao Brasil se moldavam em meio a contextos bastante variados, que se transformarão à medida que circunstâncias da política e economia mundiais se constituem e atingem a política 


\section{HISTÓRIA}

LAÇOS INCERTOS NAS RELAÇÕES POLÍTICAS ENTRE BRASIL E PORTUGAL NA DÉCADA DE 1960 Cristina luskow

e economia portuguesa frontalmente, nomeadamente as Guerras Coloniais e a Guerra Fria.

As reações do governo brasileiro ao pedido de apoio à politica portuguesa no ultramar eram de abstenção, não assumindo nenhum compromisso oficialmente. No início da ditadura militar no Brasil, Castelo Branco limitou-se a reconhecer que as soluções para o ultramar português deveriam ser encontradas dentro da soberania portuguesa. O apoio declarado à posição portuguesa por parte dos governos de Getúlio Vargas e Juscelino Kubitschek terminara com os governos de Jânio Quadros e João Goulart (MAGALHÃES, 1999, 107-108). Portanto os laços não estavam mais tão firmes como outrora, e o grande entrave se encontrava na política colonial portuguesa na África.

O número anteriormente citado da Luso-Brasileira faz várias referências à política e cultura portuguesa e europeia, e só em pouquíssimos espaços nas suas páginas o Brasil está representado. Essa variação de temas direcionados ora ao público português, ora ao público leitor brasileiro é comum na revista ao longo da sua publicação. Assim, neste número os acontecimentos destacados tem um significado e são elaborados pela revista de forma a evidenciar o sentimento de pertencimento da comunidade portuguesa ao seu país de origem. A identidade da revista se constrói a partir das conexões que faz com o grupo que representa e para o qual as notícias são majoritariamente redigidas, a partir das posições políticas que defende no Brasil e em Portugal e a partir do conteúdo das matérias de entretenimento, das tirinhas, do conteúdo religioso. Sônia de Meneses Silva afirma sobre jornal que [...] é sempre com uma intenção formuladora de identidade que o evento midiático memorável se estrutura. [...] a memória sempre é colocada a serviço de uma busca de construção de identidade (SILVA, 2011, 202). A narrativa que encontramos nas revistas passam também por essa busca de identidade. Na Luso-Brasileira podemos entrever essa elaboração identitária que se constrói por meio das aproximações entre jornal, leitores e eventos. Qual identidade se busca construir com essa memória?

As respostas por meio de cartas e telegramas de todo o mundo à "Operação Salazar", sugerida pela revista em razão da situação de saúde pela qual Oliveira Salazar passava, denotam uma preocupação latente da Luso-Brasileira por este momento crítico da política portuguesa. Em 3 de agosto de 1968, em sua residência 


\section{HISTÓRIA}

LAÇOS INCERTOS NAS RELAÇÕES POLÍTICAS ENTRE BRASIL E PORTUGAL NA DÉCADA DE 1960 Cristina luskow

de férias no Forte de Estoril, Salazar sentou-se pesadamente numa cadeira de lona e num desequilíbrio caiu e bateu com a nuca no chão de pedra do terraço (MENESES, 2011, 643). A partir daquele momento sua saúde nunca mais iria se recuperar. Na revista, a matéria que trata essa notícia traz abaixo da imagem de uma mesa coberta com cartas e em primeiro plano uma foto de Salazar. Abaixo um pequeno texto: Avolumam-se a cada momento os telegramas e cartas de todo o mundo, com votos de melhoras ao Presidente Salazar. A mesa está repleta de mensagens (Luso-Brasileira, $\mathrm{n}^{\circ} 68$, dez. 1968, p. 3). Planeja-se aproximar do contexto político de Portugal a comunidade portuguesa nos locais em que a revista circulava e assim possibilitar uma união da comunidade portuguesa pelo mundo. A revista produz um diálogo com os dilemas do tempo a partir das referências a questões prementes da política portuguesa.

Revistas são publicações que exigem uma atenção a algumas questões como, por exemplo, o público a que se direcionam, as temáticas envolvidas na publicação, quem escreve no periódico, por vezes as posições políticas dos redatores, da direção e também qual o intuito do periódico quando da sua publicação, esses são temas que se poderia designar como as três "vozes" aparentes na publicação: a revista, com suas posições políticas, opiniões e críticas, o autor que escreve o texto, que pode ter certas divergências em relação ao posicionamento da voz da revista, e as vozes daqueles retratados na revista. As revistas se apresentam na sua particularidade como imprensa periódica e também conceitualmente muito mais como entretenimento do que informação, no entanto muitas delas conseguiram ao longo do tempo agradar a vários públicos. Esse público variado era atraído muitas vezes por meio de capas diversas, a um tema por vezes mais divertido ou ligado a pessoas da sociedade, no entanto temas que tratavam de outros assuntos eram propostos e dados à leitura somente ao abrir-se a revista, no interior da publicação, que apresentava por sua vez questões concernentes normalmente à política e economia.

A Luso-Brasileira pelo seu formato, capa e conteúdo é um desses periódicos que apresentava-se aparentemente como entretenimento, mas também como informativa e noticiosa. Portanto, para isso os editores através dos correspondentes traziam notícias sempre atualizadas de Portugal, fossem estas econômicas, fossem artístico-culturais. Por meio dessas notícias, informações, contos e crônicas que permeavam o periódico vais se difundindo ao longo dos 20 anos da publicação, a 


\section{HISTORIA}

LAÇOS INCERTOS NAS RELAÇÕES POLÍTICAS ENTRE BRASIL E PORTUGAL NA DÉCADA DE 1960 Cristina luskow

cultura portuguesa, ou uma cultura política de Portugal para Florianópolis, de Portugal para o mundo. E essa difusão se fazia necessária dentro da lógica de propaganda portuguesa, à medida que se partia da ideia de que era preciso cultivar a comunidade portuguesa pelo mundo onde quer que estivesse. Era uma forma de unir os habitantes da nação portuguesa emigrada. Essa "nação" fora de Portugal deverá ser incluída no mesmo sentimento nacionalista do português que vive em Lisboa, no Porto ou em outra cidade qualquer de Portugal.

Há um intuito aqui de procurar compreender como se dá o imbricamento entre uma história do Estado Novo português e a história da revista Luso-Brasileira, no contexto político-cultural brasileiro. E como esta publicação articula um regime que já se desenvolve há 40 anos, com algumas transformações nesse período, com a cidade de Florianópolis e com o seu público leitor que são brasileiros e portugueses.

A cultura política, o processo de sua difusão na sociedade, afirma Serge Berstein, é provável que se dê através dos numerosos e difusos canais de socialização política. E continua,

\footnotetext{
A família, o sistema de ensino, o serviço militar, os locais de trabalho e sociabilidade, os grupos ou associações e as mídias vão aos poucos incutindo temáticas, modelos, argumentações, criando assim um clima cultural que prepara para aceitar como natural a recepção de uma mensagem de conteúdo politico (BERSTEIN, 2009, 39).
}

Vários são os meios pelos quais uma determinada cultura política vai sendo incutida, e a mídia é um desses, que prepara o clima cultural para aceitação de uma mensagem de conteúdo político. Os periódicos, de acordo com esse entendimento, fazem essa elaboração, através de leituras, imagens e notícias que pouco a pouco incutem uma proposta política determinada. E conclui Berstein que a força de uma cultura política está em difundir seu conteúdo por meios que, sem serem claramente políticos, conduzem, no entanto a uma impregnação política (BERSTEIN, 2009, p. 39). A revista, objeto deste trabalho, não é um meio claramente político, mas a impregnação política a que conduz, é percebida nas várias seções espalhadas pelo periódico.

Nessa direção, este texto vai mostrando a construção da representação das ideias políticas que se constroem na Luso-Brasileira em matérias pontuais apresentadas pela revista. Ainda na edição de dezembro de 1968 um título aponta 
LAÇOS INCERTOS NAS RELAÇÕES POLÍTICAS ENTRE BRASIL E PORTUGAL NA DÉCADA DE 1960

informações sobre o ditador, com o título Salazar chegava sempre ao fim do mês sem ter dinheiro afirmando o seguinte:

\begin{abstract}
Numa entrevista à jornalista francesa Christine Garrier, para o livro 'Férias com Salazar', encontramos este depoimento de Oliveira Salazar. Diz a jornalista: - "Salazar, por exemplo, chegava sempre ao fim do mês sem dinheiro, era ele quem pagava as suas despesas domésticas, o gás e luz e afirmava Salazar então, que no dia em que abandonasse o poder, quem Ihe virasse os bolsos, só encontraria pó". Um chefe de Governo extraordinário, que governou Portugal, durante 40 anos e cinco meses... (Luso-Brasileira, $\mathrm{n}^{\circ}$ 68, dez, 1968, p. 5).
\end{abstract}

São palavras de elogio ao governante português apresentadas pela revista, em primeiro lugar expressando sua postura de homem simples e trabalhador, igualandoo ao cidadão comum, depois atribuindo a ele o título de chefe extraordinário, governando Portugal por 40 anos. O termo "extraordinário" registrado pelo periódico o coloca posicionado ao lado do regime ditatorial português. Num momento de fragilidade do regime as notícias demonstrando a força e ética do ditador, legitimam a sua história e a sua importância no contexto político até aquele momento vivido por Portugal. É preciso perceber estes posicionamentos por meio das notícias e tal como afirma Marialva Barbosa, procurar reinterpretar o ontem, entendendo o hoje, pois a história não fala do tempo de ontem, possibilitando apenas a reconstrução do ontem. No diálogo com as fontes, se articula o passado e o presente, para tão somente reconstruir o passado e entender melhor o presente, com isso se faz história (BARBOSA, 1995, 88).

Tania Regina de Luca $(2005,122)$ afirma que apesar de muitas revistas se autodenominarem "de variedades", é possível perceber a intenção de atingir públicos diversos e eram ao mesmo tempo, femininas, masculinas, infantis, esportivas, pedagógicas, educacionais, voltadas ao teatro, rádio, cinema, religião e acrescentaria aqui também, política. E assim, nesta composição de temas e públicos, os editores tem um papel crucial, pois terão o intuito de reunir os redatores, imagens e notícias, que contrariamente ao que se poderia pensar em relação às revistas, está longe da "neutralidade". Nitidamente nas matérias da Luso-Brasileira, conforme afirma De Luca, não há intenção de neutralidade.

Ainda conforme Marialva Barbosa, o jornal, e aqui pode-se transpor essa análise para as revistas 


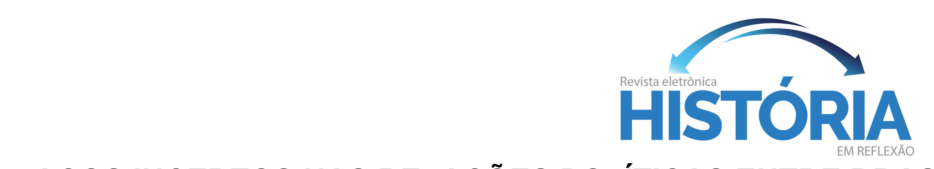

LAÇOS INCERTOS NAS RELAÇÕES POLÍTICAS ENTRE BRASIL E PORTUGAL NA DÉCADA DE 1960 Cristina luskow

ao selecionar fatos, ao relegar outros ao esquecimento, ao escolher a forma de sua narrativa, ao definir o lugar na página a ser ocupado pelo texto, dirigindo um olhar subjetivo sobre o acontecimento, mantém, como essencial a dialética lembrar/esquecer (BARBOSA, 1995, 88).

Há na totalidade da política e cultura brasileira e portuguesa diversos assuntos que se procura evidenciar/lembrar e outros mais que é importante e necessário deixar esquecido, e assim a revista articula os conteúdos jornalísticos nas suas páginas.

Nessa direção menciono uma das seções da revista intitulada: As Aventuras de Fidel, página inteira com quatro tirinhas em preto e branco, cada uma exibindo uma história diferente (Figura 2). Na terceira tira há um diálogo entre o personagem que representa Fidel Castro e um cidadão comum, este com aparência simples, chapéu de palha e descalço. No diálogo o personagem Fidel afirma: Sempre fui marxistaleninista! Jamais colaborei com o regime capitalista... E então o cidadão afirma: - E claro: nunca trabalhou em toda a sua vida!... (Luso-Brasileira, n68, dez, 1968, p.16). A publicação faz críticas severas ao comunismo por meio das tirinhas. O combate ao comunismo era uma bandeira importante do salazarismo, e no contexto político brasileiro e de Guerra Fria, essas posições se adequavam acertadamente a esses dois contextos. As tirinhas permeiam inúmeros exemplares da publicação e as críticas se dão também por outros meios, como contos e as próprias notícias de fatos políticos.

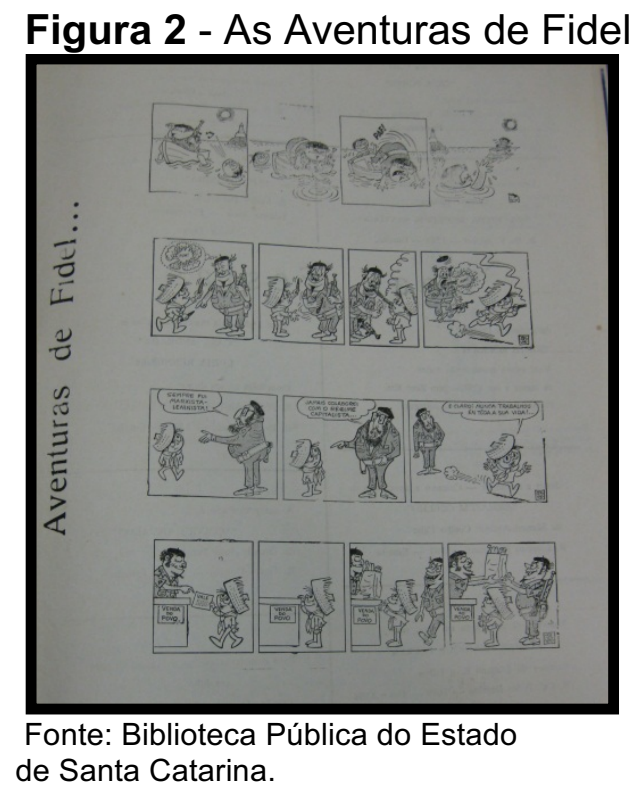

O contexto político de então no Brasil é de uma ditadura militar que se iniciou em abril de 1964, e em 1968, ano do número da revista analisada, era forte o rigorismo 


\section{HISTÓRIA \\ LAÇOS INCERTOS NAS RELAÇõES POLÍTICAS ENTRE BRASIL E PORTUGAL NA DÉCADA DE 1960 Cristina luskow} da censura política no Brasil. Em 1968 é editado o Ato Institucional número 5 (Al-5) o qual significou a quebra de legalidade imposta pelo próprio regime, dando poderes quase ilimitados ao presidente da República para legislar por decreto e suspender direitos políticos dos cidadãos, por exemplo (RIDENTI, 2014, 36). A Luso-Brasileira em sua narrativa adota a luta contra o comunismo, alinhando-se à posição do governo militar no Brasil, como se evidencia no quadrinho descrito acima. As críticas explícitas ao governo comunista de Fidel Castro em Cuba, demonstradas pelo cidadão trabalhador que acusa o personagem Fidel de nunca ter trabalhado, simbolizam o "comunista" que vive na dependência do Estado em oposição ao "capitalista" que trabalha para conseguir sobreviver. Estas cenas apresentam os choques com 0 comunismo que se dão nas ditaduras tanto no Brasil como em Portugal.

Como abordado no início deste artigo, as relações entre Portugal e Brasil haviam sofrido algumas mudanças após o golpe militar em 1964, tornando-se menos hostis que nos governos de Jânio Quadros e João Goulart, no entanto ainda com reticências devido à política colonialista do Estado Novo. Escrevia Alceu de Amoroso Lima ${ }^{5}$, importante escritor, filósofo social, crítico literário e professor brasileiro, o Tristão de Athayde em 27 de agosto de 1965 no Jornal do Brasil:

Devemos respeitar o direito que tem Portugal de se opor à independência de suas colônias. Mas daí a ligarmos nosso destino político a esse colonialismo, que temos também o direito de considerar agonizante, vai um abismo que não devemos de modo algum transpor (Jornal do Brasil, 1965, 1).

No entanto, as notícias veiculadas pela revista, em referência ao tema das relações coloniais, corroboravam a política exterior de Portugal relativas às colônias portuguesas, ou "províncias ultramarinas", termo utilizado pelo Estado Novo a partir de 1951 para se referir a elas. Tal mudança na nomenclatura, no entanto não provocou grandes transformações na prática administrativa portuguesa na África. A despeito das críticas anticolonialistas impostas pela conjuntura mundial após a Segunda Guerra Mundial, Portugal passaria a justificar sua presença no ultramar

\footnotetext{
5 “Alceu Amoroso Lima nasceu no Rio de Janeiro, em 1893. [...] Em 1919 iniciou sua colaboração em O Jornal como crítico literário, passando a utilizar o pseudônimo de Tristão de Ataíde. [...] Após o golpe militar de 1964, notabilizou-se por seu posicionamento contrário ao novo regime em sua coluna no Jornal do Brasil. Seu enorme prestígio intelectual possibilitou-lhe, inclusive, romper o cerco da censura imposto ao país. Em 1967 foi nomeado pelo papa Paulo VI membro da Comissão de Justiça e Paz, com sede em Roma" (CPDOC-FGV. A Era Vargas: dos anos 20 a 1945 - Alceu Amoroso Lima).
} 


\section{HISTÓRIA}

LAÇOS INCERTOS NAS RELAÇÕES POLÍTICAS ENTRE BRASIL E PORTUGAL NA DÉCADA DE 1960 Cristina luskow

enfatizando a ideia de que estaria realizando uma missão civilizadora nos trópicos (PEIXOTO, 2009, 17).

Na seção Presença de Portugal, edição de dezembro 1968 a Revista LusoBrasileira apresentou a foto de um casal da Guiné Portuguesa (nome da atual GuinéBissau, quando colônia portuguesa) com Américo Tomáz, presidente da República Portuguesa, de 1958 a 1974. Ao lado da foto o pequeno texto: Representantes da Guiné Portuguesa foram a Lisboa, e conversaram longamente com o sr. Almirante Américo Tomáz (Luso-Brasileira, n68, dez, 1968, p.7). É notável na imagem, os representantes guineenses com trajes típicos da cultura africana, vestindo roupas brancas, mantos, colares e turbante, ao lado do representante português. Somente Tomáz teve o nome citado no texto, diferentemente dos representantes do país africano. Na foto, a imagem que o leitor tem é de uma conversa tranquila e amigável, sem tensões. No entanto esse é um período de sérios conflitos com as antigas colônias africanas, e a Guiné Portuguesa passava por uma guerra pela independência iniciada em 1963. São impressões de uma imagem que é recorrente na revista, e que neste momento apontam o posicionamento da publicação em relação à política ultramarina portuguesa, que neste caso, ostenta um aparente contexto de negociação, deixando a imagem falar por si, a qual dá espaço para uma interpretação de paz entre Portugal e a Guiné Portuguesa.

No número da revista de maio de 1969 são veiculadas mais imagens para demonstrar um clima amigável entre a Guiné Portuguesa e o governo português. Ao lado de uma foto em que várias pessoas aclamam a passagem do então Presidente do Conselho, Marcelo Caetano por Bissau, capital da Guiné, vê-se o seguinte texto: A viagem histórica do Presidente Dr. Marcelo Caetano ao ultramar português. Fotos especiais para a Luso-Brasileira: Em Bissau, capital da Guiné Portuguesa, o Governador saúda o Sr. Presidente Dr. Marcelo Caetano (Luso-Brasileira, nº72, maio, $1969,7)$. As fotos especiais para a Luso-Brasileira indicam o envolvimento do periódico local no conflito na África.

Como afirma Maria Helena Capelato $(1998,67)$ sobre a propaganda no varguismo e peronismo: [...] os encarregados da propaganda procuraram aperfeiçoarse na arte da empolgação e envolvimento das 'multidões' através das mensagens políticas. Cita Goebbels quando afirma que não falamos para dizer alguma coisa, mas 


\section{HISTÓRIA}

LAÇOS INCERTOS NAS RELAÇÕES POLÍTICAS ENTRE BRASIL E PORTUGAL NA DÉCADA DE 1960 Cristina luskow

para obter determinado efeito (CAPELATO, 1998, 67). Respeitando as devidas proporções com as práticas nazi-fascistas, é possível dizer que essas imagens ao se espalhar através da Revista Luso-Brasileira por várias cidades no mundo, tenha esse intuito, de obter um efeito, o qual seria o de legitimar e justificar a presença do domínio português nas suas colônias. Essa posição da revista se coloca a despeito da política brasileira, oposta à política colonialista ultramarina portuguesa naquele momento. São códigos e conjuntos de referentes que vão se formando (BERSTEIN, 2009, 350) que criam representações de uma determinada política, tais códigos, com origem em diferentes grupos se imbricam no interior de culturas políticas diversas de Portugal e do Brasil e possibilitam o surgimento de novos conjuntos de referentes.

Nesta página e na seguinte a revista apresenta diversas imagens que representam a "festa" nos países africanos pela visita de Marcelo Caetano a Guiné Portuguesa e Angola. São representações do país que apagam ou tentam apagar os conflitos existentes. Diante disto há uma concordância com Capelato $(1998,57)$ quando diz que o imaginário da unidade mascara as divisões e os conflitos existentes na sociedade. Reinhart Koselleck afirma que língua e história, fala e ação não coincidem. Todo texto diz, ao mesmo tempo, mais e menos e, em todo caso, também algo diferente daquilo que realmente possa ter sido o caso. Nessa diferença reside a multiplicidade das explicações possíveis (KOSELLECK, 2014, 57). Portanto, ao fazer a análise e pensar a história se delineando a partir desses acontecimentos e da forma como são narrados pela Revista Luso-Brasileira é preciso como propõe Koselleck (2014, 58): escolher, elaborar novas perguntas e interpretar de maneira nova possibilitando-se assim vislumbrar algo diferente do que pode ter acontecido. Ao se perceber que língua e história não coincidem nas 'vozes' da revista, é preciso um olhar mais atento que busca perceber nos indícios as suas propostas, projetos políticos e concepções.

\section{REFERÊNCIAS}

ATHAYDE, Tristão de. "Recolonização inconfessada". Jornal do Brasil, Rio de Janeiro, p.1, 27 de agosto de 1965. ed. 00200. Acesso em 11 mar 2017. Disponível em:

$<$ http://memoria.bn.br/DocReader/docreader.aspx?bib=030015 08\&pasta=ano\%201 96\&pesq=1965> 


\section{HISTÓRIA}

LAÇOS INCERTOS NAS RELAÇÕES POLÍTICAS ENTRE BRASIL E PORTUGAL NA DÉCADA DE 1960 Cristina luskow

BARBOSA, Marialva. Senhores da memória. In: Intercom - Revista Brasileira de Ciências da Comunicação, v. 18, n. 2 (1995)

BERSTEIN. Culturas políticas e historiografia. In: AZEVEDO, Cecília et al (orgs.). Cultura política, memória e historiografia. Rio de Janeiro: FGV, 2009.

CAPELATO, Maria Helena Rolim. Multidões em cena. Propaganda política no varguismo e no peronismo. Campinas, SP: Papirus, 1998.

CPDOC-FGV. A Era Vargas: dos anos 20 a 1945 - Alceu Amoroso Lima. Acesso em 10 mai 2018. Disponível em:

<http://cpdoc.fgv.br/producao/dossies/AEraVargas1/biografias/alceu_amoroso lima>

DE LUCA, Tânia Regina. A Revista do Brasil: um diagnóstico para a (N)ação. São Paulo: Fundação Editora UNESP, 1999.

. Leituras, projetos e (Re)vista(s) do Brasil (1916-1944). São Paulo: Editora Unesp, 2011.

KOSELLECK, Reinhart. Estratos do tempo: estudos sobre história. Rio de Janeiro: Contraponto: PUC-Rio, 2014.

MAGALHÃES, José Calvet. Breve história das relações diplomáticas entre Brasil e Portugal. São Paulo: Paz e Terra, 1999.

MENESES, Filipe Ribeiro de. Salazar: biografia definitiva. São Paulo: Leya, 2011.

MOTTA, Rodrigo Patto Sá. Desafios e possibilidades na apropriação de cultura política pela historiografia. In.: Culturas Políticas na História: Novos Estudos. Belo Horizonte: Argumentum, 2009. p.21.

MOTTA, Rodrigo Patto Sá; REIS, Daniel Aarão; RIDENTI, Marcelo (Org.). A ditadura que mudou o Brasil - 50 anos do golpe de 1964. Rio de Janeiro: Zahar, 2014.

PEIXOTO, Carolina Barros Tavares. Limites do Ultramar Português, possibilidades para Angola: o debate político em torno do problema colonial (1951-1975). (Dissertação) UFF, 2009.

PORTUGAL, Gabinete do Secretário de Estado das Comunidades Portuguesas Relatório da Emigração, 2013.

RODRIGUES, Weslei Estradiote. "Meu Portugal é a aldeia": etnografia de uma dinâmica de circulação migratória e práticas transnacionais. (Tese) São Paulo, USP, 2013.

SILVA, Sonia Maria de Meneses. A operação midiográfica: a produção de acontecimentos e conhecimentos históricos através dos meios de comunicação - a 


\section{HISTÓRIA}

LAÇOS INCERTOS NAS RELAÇÕES POLÍTICAS ENTRE BRASIL E PORTUGAL NA DÉCADA DE 1960

Cristina luskow

Folha de São Paulo e o golpe de 1964. Tese. Doutorado em História. Universidade Federal Fluminense, 2011.

SIRINELLI, Jean-François. Os intelectuais. In.: Por uma história política. 2ed. Rio de Janeiro: FGV, 2003.

SOUSA, Vitor. O Estado Novo, a cunhagem da palavra 'portugalidade' e as tentativas da sua reabilitação na atualidade. Estudos em Comunicação. $n^{\circ} 25$, vol. 1, 287-312 Dezembro de 2017.

THOMAZ, Omar Ribeiro. "O Bom Povo Português": Usos e Costumes D’Aquém e D’Além-Mar. MANA 7 (1):55-87, 2001. p. 55-87.

\section{FONTES}

Revista Luso -Brasileira - dezembro de 1968.

- maio de 1969.

Jornal do Brasil 27 de agosto de 1965.

Recebido em 11/03/2018

Aceito em 02/06/2018 